TEXT Vol 13 No 1 April 2009

\title{
Editorial
}

\section{TEXT in the A rank}

It's a nightmare of acronyms, but a good-dream result. In the new ERA (Excellence in Research for Australia) HCA (Humanities and Creative Arts) journal list released by the ARC (Australian Research Council), TEXT has achieved an A ranking (see entry No. 7093 at http://www.arc.gov.au/era/journal_list.htm). This means TEXT is included in the top $23.3 \%$ of the 7,500 journals rated. Overall, $46.5 \%$ were ranked $\mathrm{C}$, $30.2 \%$ were $\mathrm{B}, 17.5 \%$ were $\mathrm{A}$, and just 436 or $5.8 \%$ were ranked $\mathrm{A}^{*}$.

This is an excellent result for TEXT. In our thirteenth year of publication and representing a wholly new discipline in Australia, to be in the top quartile of national and international journals (at least in the Australian government's eyes) is a great achievement. We knew we were up against the odds because a) there seemed to be a bias against web-based journals and b) we were unsure of the academic status given to creative writing studies. This rating dispels our concerns on both accounts, but we cannot rest on our laurels. The rankings will continue to be reviewed. This also means that we have an opportunity to rise and join the gods of the $\mathrm{A}^{*}$ ranking in the future.

Clearly responsible for this result is the work put in by contributors and referees over the last 13 years. The dynamic created by these two sectors of our publishing process has always been supportive and led us forward. We have an important, lively journal because of this. Also contributing to our A ranking were the submissions to the ARC from universities around Australia. On behalf of you all, the makers and readers of TEXT, thank you to the writing academics who made submissions. This has been a significant result.

Writers in the academy have well over a decade of published scholarly research behind them now, and this, along with the decades of teaching writing within university settings, has provided a considerable range of topics for consideration, experience from which to generate data, and issues that demand analysis. This issue of TEXT contains essays that develop and expand knowledge, thought and scholarship in and about writing. Some deal with craft: Genevieve Kaplan explores contemporary thinking about ekphrasis, for instance; Gay Lynch teases out the particularities of life writing through a reading of Kate Grenville; Dominique Hecq attends to the complexities involved in translation; and Christopher Bowman connects voice and place. Others deal with institutional issues. Mark Carthew discusses the perplexities, opportunities and absences associated with being an early career researcher in the university setting; Nicola Boyd lays out her research into creative writing higher degrees research; and both Donna Lee Brien and Camilla Nelson take on the issue of peer review - in Brien's case, as part of a critical investigation of the system of peer review and its evaluative structures; in Nelson's case, as an experiment into how peer review operates with regard to fictional work. These last four have each, and independently, turned their attention to the policy and procedural frameworks that act to formalise (and delimit) research practice, in 
writing and in other disciplines. Each essay draws attention to a problem of research structures: their failure to deliver what they seem to promise.

Formally, all Australian universities and government bodies work from the internationally accepted definition of research:

creative work undertaken on a systematic basis in order to increase the stock of knowledge, including knowledge of man, culture and society, and the use of this stock of knowledge to devise new applications. (OECD 2002)

But practice, as so often is the case, does not perfectly accord with theory. Researchers have faced more than a decade of funding restrictions, and now universities additionally face ongoing financial pressures, demographic changes, technological developments, shifting discourses about intellectual and scholarly pursuits, and a staggering range of national, international and local restructures and assessments. It is little wonder, then, that the ideal of the OECD definition is frequently overlooked in the battle to acquire funds, compete for students and resources, and attempt to push back the tsunamis of paperwork that fill desk and desktop of every academic. Thus, though we can all agree that, for instance, peer review should facilitate the dissemination of high quality contributions to knowledge, the attachment of economic and other extra-research evaluative mechanisms, as well as pressures on time and attention, militate against this certain outcome.

The response to the global financial crisis seems to be homeopathic: governments see the cause of the illness as its remedy, and aim to spend our way out of the problem. The response to the pressures faced by academics likewise seems homeopathic: deal with the expressed lack of time for research by adding administrative duties to the average workload; run another institutional review; change the way we collect and record data. TEXT has published a number of articles that confront the problem of time and attention faced by writing academics, and the spreading thin of our energies and passion. These papers extend that discussion by incorporating an investigation of broader, institutional issues that impact on research practice, and confront the latent effects of neoliberal and managerial practices in the academic field.

These are timely articles, written and published in the year in which Australian universities are preparing for the trial run of the Excellence in Research for Australia evaluation system, and when the Humanities and Creative Arts cluster is (with Physical, Chemical and Earth Sciences) first off the block. It will not be a perfect system; already a number of discussions and seminars have pointed out its flaws. But academics have no choice in the matter: the whole package that is institutionalised research may be a flawed game, but it's the only game in town, for those of us who want to contribute to knowledge from within the academy. We must play that game, and find ways to fit our work within the discourses of 'excellence', or knowledge.

But we need not meekly accept this discourse, however dominant it might be, especially where it does not meet our needs or allow space for our research paradigm. Of all the disciplines, it is those structured around creative practice that are, arguably, best placed to deform or transform the field. We have done this already, we writers and painters, dancers and sculptors: to use Michel de Certeau's term (1984: xii), we have already 'insinuated' ourselves and our practices into the academy, making something else of the terms and procedures that were at stake, and in the process have already shifted some of the terms of reference. Our work counts as research - in however qualified a fashion. The work of our higher degrees students is recorded among the contributions to 
knowledge generated each year, despite the problems of information and access identified by Boyd in this issue. Still, a grid has been dropped over the academy, it seems, and it is likely to restrict or redirect our activities. It is important that we, like academics in other disciplines who are equally caught in its strictures, look at this grid with clear and analytical eyes, and find ways both to resist it overtly where appropriate, and to deform it more covertly: find ways to operate that will allow us the space - physical, intellectual and financial - to play the game to which we have committed ourselves. TEXT would welcome further contributions that lay out data, and provide analysis, of what does and does not work in the research system that seeks to shape our practice, and of how we might productively intervene in - and contribute to - that system.

Jen Webb

Nigel Krauth

Certeau, Michel de 1984 The practice of everyday life (trans Steven Rendall), Berkeley: University of California Press return to text OECD 2002 Frascati Manual: Proposed Standard Practice for Surveys on Research and Experimental Development, OECD: Paris return to text

\section{TEXT}

Vol 13 No 1 April 2009

http://www.textjournal.com.au

Editors: Nigel Krauth \& Jen Webb

Text@griffith.edu.au 